\title{
Preparation, characterization and thermal decomposition of sodium and potassium salts of dithiocarbamate
}

\author{
L. A. Ramos ${ }^{1}$, E. T. G. Cavalheiro ${ }^{2 *}$ \\ ${ }^{1}$ Departamento de Físico-Química, Instituto de Química de São Carlos, Universidade de São Paulo, Avenida do Trabalhador São-carlense, 400, \\ 13560-970, São Carlos - SP - Brazil. \\ ${ }^{2}$ Departamento de Química e Física Molecular, Instituto de Química de São Carlos, Universidade de São Paulo, Avenida do Trabalhador São-carlense, 400, \\ 13560-970, São Carlos - SP - Brazil. \\ Received 07/06/2013; accepted 11/12/2013 \\ Available online $18 / 12 / 2013$
}

\begin{abstract}
Pyrrolidinedithiocarbamate (Pyr), piperidinedithiocarbamate (Pip), morpholinedithiocarbamate (Mor), diethanolaminedithiocarbamate (DEDC) and hexamethylenedithiocarbamate (Hex) sodium and potassium salts, were synthesized, characterized by IR, elemental analysis, ${ }^{1} \mathrm{H}$ and ${ }^{13} \mathrm{C}$ NMR and their thermal behaviors were investigated using thermogravimetry (TG) and differential scanning calorimetry (DSC). The decomposition of sodium salts occurred in different manner depending on the nature of the substituent, generating sodium polysulphides. The potassium salts decomposed via thiocyanate as predicted in the literature.
\end{abstract}

Keywords: Diethanolaminedithiocarbamate, DSC, hexamethylenedithiocarbamate, morpholinedithiocarbamate, piperidinedithiocarbamate, Pyrrolidinedithiocarbamate, TG, thermal decomposition.

\section{Introduction}

Dithiocarbamates (DTC) are the reaction products between primary or secondary amine and carbon disulphide in basic media. Depending on the nature of the amine used in the synthesis of these compounds, mono or dialkyldithiocarbamates are formed.

Dithiocarbamates have been studied extensively over last decades in a response to their growing applications in many new areas of chemistry, industry and medicine [1- $\underline{3}$. They have also been used in agriculture as insecticides, herbicides and fungicides. Additional uses are as biocides for industrial or other commercial applications, and in household products. Some are used as vector control in public health [4]. The thermochemistry of metal dithiocarbamate has been extensively reported and reviewed [5-10].

Despite their importance as reaction intermediates and precursors of metallic complexes the sodium and potassium salts of dithiocarbamates are rarely described in the literature in relation to their thermal properties [11-13]. In addition, it should be noted that the preparation of potassium salts is not so easy to perform since the yields are usually very low, this new synthesis strategies are important in order to improve the quantity of salts prepared in a reaction procedure $[\underline{14}, \underline{15}]$.

In this sense few is known about diallyldithiocarbamates salts of the general formula $\mathrm{M}\left[\mathrm{S}_{2} \mathrm{CNR}\right] ; \mathrm{M}=\mathrm{Na}^{+}$or $\mathrm{K}^{+}$, and $\mathrm{R}=$ pyrrolidine $(\mathrm{Pyr})$, piperidine (Pip), morpholine (Mor), hexamethylene (Hex), diethanolamine (DEDC) regarding their thermal behavior [16]. These salts are used to prepare the complexes with general formula $\mathrm{ML}_{2}\left(\mathrm{M}=\mathrm{Ag}^{+}, \mathrm{Co}^{2+}, \mathrm{Cu}^{2+}, \mathrm{Fe}^{3+}, \mathrm{Hg}^{2+}\right.$,
$\mathrm{Mn}^{2+}, \mathrm{Ni}^{2+}$ and $\mathrm{Zn}^{2+}$ ) whose thermal behavior were described earlier [17-22]. Considering their relevance and the few data described the present work deals with the thermal analysis (TG/DTG and DSC) study of $\mathrm{Na}\left[\mathrm{S}_{2} \mathrm{CNR}\right]$ and $\mathrm{K}\left[\mathrm{S}_{2} \mathrm{CNR}\right]$ in order to contribute the understanding their thermal decomposition pathway.

\section{Experimental}

\subsection{Synthesis and characterization of DTC salts}

The $\mathrm{Na}^{+}$salts of the dithiocarbamates were prepared by slow addition of $0.1 \mathrm{~mol}$ of $\mathrm{CS}_{2}$ to a cold mixture containing $0.1 \mathrm{~mol}$ of the amine (pyrrolidine, piperidine, morpholine, hexamethyleneimine or diethanolamine) and $0.1 \mathrm{~mol}$ of sodium hydroxide dissolved in $30 \mathrm{~mL}$ of ethanolwater 1:1 $(v / v)$. During the reaction the mixture was kept in an ice bath. The resulting solids were recrystallised in a minimum volume of ethanol-water 1:1 ( $/ \mathrm{v})$ filtered in syntherized glass filters and dried in a vacuum oven at $50^{\circ} \mathrm{C}$ for $8 \mathrm{~h}[\underline{13}, \underline{21}]$.

The $\mathrm{K}^{+}$salts of the dithiocarbamates were prepared in similar way, by slow addition of $0.1 \mathrm{~mol}$ of $\mathrm{CS}_{2}$ to a cold mixture containing $0.1 \mathrm{~mol}$ of the amine (pyrrolidine, piperidine, morpholine, hexamethyleneimine or diethanolamine) and $0.1 \mathrm{~mol}$ of potassium hydroxide dissolved in $30 \mathrm{~mL}$ of isopropyl alcohol-water 5:1 ( $\mathrm{v} / \mathrm{v})$. During the reaction the mixture was kept in an ice bath. The reaction should be conducted in isopropyl alcohol/water 5:1 $(\mathrm{v} / \mathrm{v})$ as solvent in order to reach the best yield according to our investigation. The resulting solids were recrystallised from isopropyl alcohol filtered in syntherized glass filters and dried in a vacuum oven at $50^{\circ} \mathrm{C}$ for $8 \mathrm{~h}[\underline{13}, \underline{21}]$. 
In all cases the reaction products were characterized by elemental analysis $(\mathrm{C}, \mathrm{N}, \mathrm{H})$, infrared spectroscopy (FTIR) and ${ }^{1} \mathrm{H}$ and ${ }^{13} \mathrm{C}$ NMR spectrum.

\subsection{Equipment}

IR spectra ( $\mathrm{KBr}$ pellets) were taken in a Bomen MB102-FTIR spectrophotometer. The $\mathrm{C}, \mathrm{H}$ and $\mathrm{N}$ contents were determined by elemental analysis using a Fisons EA 1108 CNHS-O instrument. The ${ }^{1} \mathrm{H}$ and ${ }^{13} \mathrm{C}$ NMR spectra were obtained in a Bruker ARX photometer, with $200 \mathrm{MHz}$ frequency using $\mathrm{D}_{2} \mathrm{O}$ as solvent.

The TG curves were recorded using a DuPont 2100 thermoanalyser coupled to a TGA 951 thermobalance under a $300 \mathrm{~mL} \mathrm{~min}^{-1}$ nitrogen gas flow, in a Pt crucible, at $5{ }^{\circ} \mathrm{C}$ $\mathrm{min}^{-1}$ heating rate and the samples of about $7 \mathrm{mg}$ for each compound at atmospheric pressure. Heating rate $5-20{ }^{\circ} \mathrm{C}$ $\mathrm{min}^{-1}$ and gas flow $25-300 \mathrm{~mL} \mathrm{~min}^{-1}$ were optimized prior to the thermal investigation using about $7 \mathrm{mg}$ of $\mathrm{NaPyr} .2 \mathrm{H}_{2} \mathrm{O}$ as a probe in a $\mathrm{Pt}$ crucibles. Temperature range from room temperature to $800{ }^{\circ} \mathrm{C}$.

The DSC curves were recorded in a DuPont 2100 thermoanalyser coupled to a DSC 910 module under nitrogen purging (flow rate: $300 \mathrm{~mL} \mathrm{~min}{ }^{-1}$ ), in aluminum pans, at $5^{\circ} \mathrm{C} \mathrm{min}^{-1}$ heating rate and initial sample mass was about $5 \mathrm{mg}$ for each compound at atmospheric pressure. The DSC cell was calibrated using metal In $(>99.9 \%)$ as standard for temperature and energy changes as recommended by the manufactories. Temperature range from room temperature to $600{ }^{\circ} \mathrm{C}$.

\section{Results and Discussion}

The prepared compounds are listed in Table 1 and their given formulas are in a good agreement with the elemental analyses and IR data. The formulas of ligands are presented in Figure 1. The IR spectra show double bands in the 950-1050 $\mathrm{cm}^{-1}$ range attributed to $v(\mathrm{C}-\mathrm{S})$ for all the compounds confirming their saline character [23].

Table 1. Results of the characterization of the dithiocarbamates salts: FTIR bands, and analytical data

\begin{tabular}{|c|c|c|c|c|c|c|}
\hline \multirow{2}{*}{ Compound } & \multicolumn{4}{|c|}{ Found (calc.)/\% } & \multicolumn{2}{|c|}{ FTIR bands/cm ${ }^{-1}$} \\
\hline & $\bar{C}$ & $\overline{\mathbf{N}}$ & $\overline{\mathbf{H}}$ & I & $v \mathrm{CN}$ & $\overline{v C S}$ \\
\hline NaPyr.2 $\mathrm{H}_{2} \mathrm{O}$ & $29,15(29,26)$ & $6,78(6,82)$ & 5,90 & $(5,89)$ & 1461 & 942998 \\
\hline KPyr & $31,83(32,40)$ & $7,83 \quad(7,56)$ & 4,22 & $(4,35)$ & 1461 & $947 \quad 1004$ \\
\hline $\mathrm{NaPip} .2 \mathrm{H}_{2} \mathrm{O}$ & $33,10 \quad(32,86)$ & $6,45 \quad(6,39)$ & 6,48 & $(6,43)$ & 1470 & 942999 \\
\hline KPip. $2 \mathrm{H}_{2} \mathrm{O}$ & $30,62(30,61)$ & $5,97 \quad(5,95)$ & 6,07 & $(5,99)$ & 1468 & $968 \quad 1005$ \\
\hline $\mathrm{NaMor} .2 \mathrm{H}_{2} \mathrm{O}$ & $27,65 \quad(27,14)$ & $6,46 \quad(6,33)$ & 5,64 & $(5,47)$ & 1463 & $982 \quad 1025$ \\
\hline KMor. $\mathrm{H}_{2} \mathrm{O}$ & $27,53 \quad(27,38)$ & $6,42 \quad(6,39)$ & 4,47 & $(4,59)$ & 1450 & $975 \quad 1012$ \\
\hline NaDEDC & $28,56(29,55)$ & $6,61 \quad(6,89)$ & 4,93 & $(4,96)$ & 1465 & $969 \quad 1042$ \\
\hline KDEDC & $27,77 \quad(27,38)$ & $6,49 \quad(6,39)$ & 4,60 & $(4,59)$ & 1466 & 10191033 \\
\hline $\mathrm{NaHex} .2 \mathrm{H}_{2} \mathrm{O}$ & $56,78(56,89)$ & $10,30(10,21)$ & 9,43 & $(9,55)$ & 1485 & $975 \quad 1010$ \\
\hline
\end{tabular}

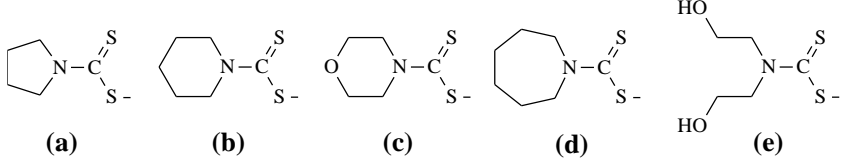

Figure 1. Formulas of dithiocarbamate derived from: (a) pyrrolidine (Pyr), (b) piperidine (Pip), (c) morpholine (Mor), (d) hexamethyleneimine (Hex) and (e) diethanolamine (DEDC).

According to the literature, a single band in this region is due to the bidentate behaviour of the ligand that causes an equivalent stretching of both $v(\mathrm{C}-\mathrm{N})$ bonds. However when a saline or monodentate behaviour is observed the $v(\mathrm{C}-\mathrm{N})$ bonds are non-equivalent and they appear in the IR spectra as doublet bands. The characteristic $v(\mathrm{C}-\mathrm{N})$ bond in the dithiocarbamates is represented by the strong absorption in the $1500-1400 \mathrm{~cm}^{-1}$ range [23].

The ${ }^{1} \mathrm{H}$ and ${ }^{13} \mathrm{C}$ NMR data are represented in Table 2 . The chemical shift of the protons and carbon signals are not markedly different for $\mathrm{K}^{+}$and $\mathrm{Na}^{+}$salts since the compounds are dissociated in aqueous phase. Small shifts can be observed depending on the nature of the amminic substituent, mainly for the oxygenated Mor and DEDC.

Table 2. ${ }^{13} \mathrm{C}-\mathrm{NMR}$ and ${ }^{1} \mathrm{H}-\mathrm{NMR}$ data for dithiocarbamates salts

\begin{tabular}{|c|c|c|c|c|c|c|c|}
\hline & Pyr & & & & EDC & & \\
\hline \multirow{2}{*}{ Compound } & \multicolumn{4}{|c|}{${ }^{3} \mathrm{C}-\left(\mathbf{D}_{2} \mathbf{O}\right) \mathbf{p p m}$} & \multicolumn{3}{|c|}{${ }^{T} \mathrm{H}-\left(\mathbf{D}_{2} \mathbf{O}\right) \mathbf{p p m}$} \\
\hline & $\delta_{1}$ & $\delta_{2}$ & $\delta_{3}$ & $\delta_{4}$ & $\delta_{2}$ & $\delta_{3}$ & $\delta_{4}$ \\
\hline NaPyr & $\begin{array}{ll}193,37 \\
\end{array}$ & 45,83 & 16,52 & -- & 3,75 & 1,96 & -- \\
\hline KPyr & 194,02 & 45,73 & 16,40 & --. & 3,73 & 1,96 & -.- \\
\hline NaPip & 196,02 & 43,89 & 16,52 & 14,66 & 4,21 & 1,56 & 1,53 \\
\hline KPip & 196,02 & 43,85 & 16,66 & 14,82 & 4,19 & 1,56 & 1,53 \\
\hline NaMor & 200,19 & 42,38 & 57,16 & -.. & 4,32 & 3,75 & --- \\
\hline KMor & 200,13 & 42,12 & 56,87 & -.- & 4,36 & 3,74 & --. \\
\hline NaDEDC & 202,08 & 50,01 & 47,63 &.-- & 4,25 & 3,87 & --- \\
\hline KDEDC & 201,82 & 49,98 & 47,57 & -.- & 4,28 & 3,94 & -.- \\
\hline NaHex & 197,64 & 46,33 & 17,64 & 17,23 & 4,13 & 1,73 & 1,53 \\
\hline
\end{tabular}

\subsection{Definitions of thermal analysis conditions}

During a preliminary study the NaPyr showed a dehydration process followed by the decomposition and formation of an unstable residue, which agrees with earlier findings [24]. After the residue formation, an oxidation can be observed, which was not expected in nitrogen. So an investigation to optimize the gas flow that could prevent this oxidative process was performed. The results are presented in Figure 2.a, in which it is possible to observe that a stable residue was obtained only at $300 \mathrm{~mL} \mathrm{~min}^{-1}$; even in pure $\mathrm{N}_{2}$ $(99.999 \%)$. This was attributed to a non-effective sealing of the furnace. However the relatively high gas flow was possible since the horizontal furnace configuration admits the gas in $90^{\circ}$ in relation to the balance arm axis, preventing turbulence. This is confirmed by the stable TG/DTG profiles.

It was also found that the heating rate influenced the TG curves. Best results were obtained when heating the sample at $5{ }^{\circ} \mathrm{C} \mathrm{min}^{-1}$, according to the data in Figure 2.b. 

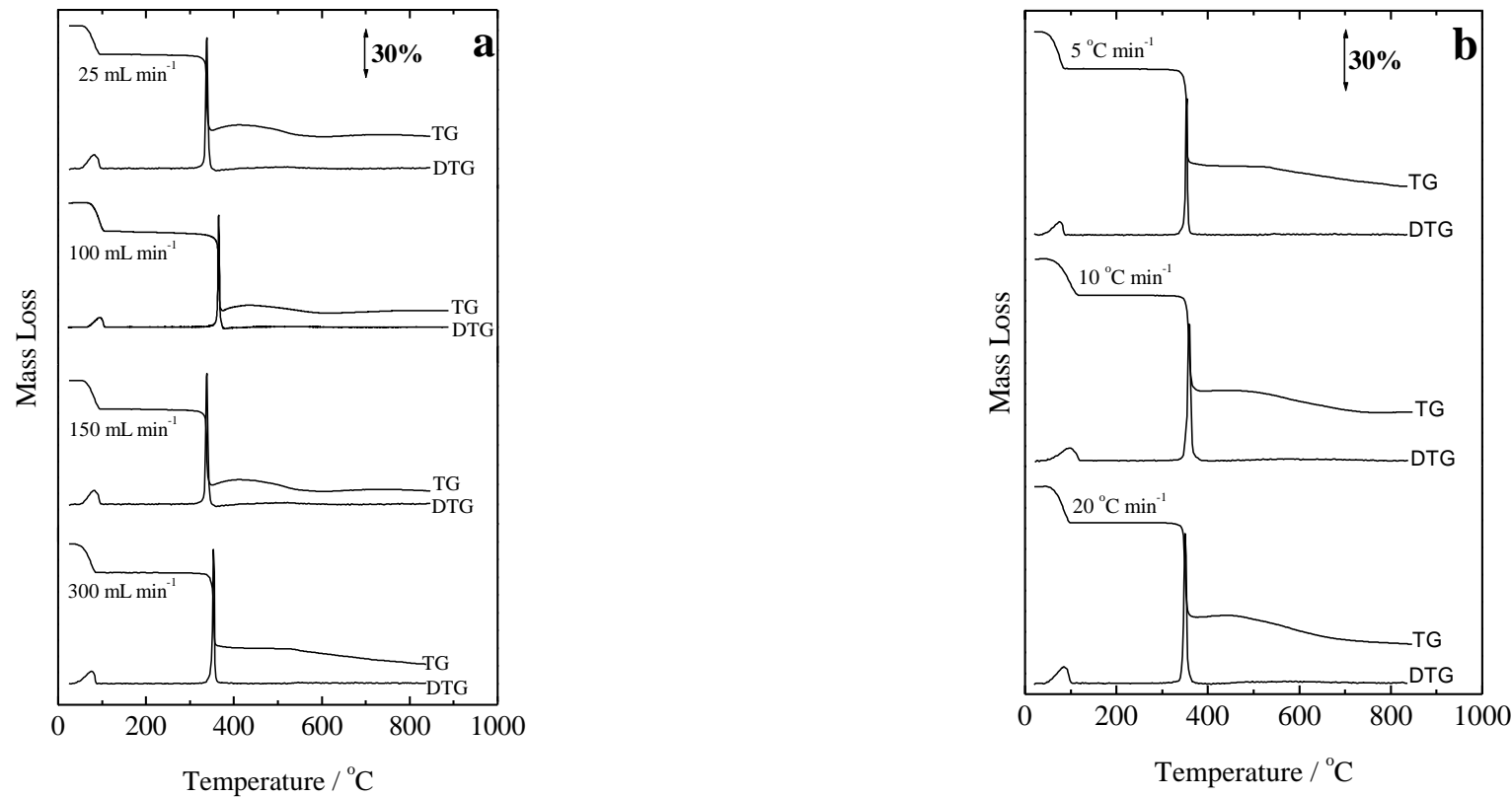

Figure 2. (a) TG/DTG curves of the sodium pyrrolidinedithiocarbamate salt in nitrogen atmosphere (sample mass ca. $7 \mathrm{mg}$, $5^{\circ} \mathrm{C} \min ^{-1}$, Pt crucible, $\mathrm{N}_{2}$ flow $25,100,150$ and $300 \mathrm{~mL} \mathrm{~min}^{-1}$ ). (b) TG/DTG curves of the sodium pyrrolidinedithiocarbamate salt in nitrogen atmosphere (sample mass ca. $7 \mathrm{mg}, 5^{\circ}, 10^{\circ}$ and $20^{\circ} \mathrm{C} \mathrm{min}^{-1}$, $\mathrm{Pt}$ crucible, $\mathrm{N}_{2}$ flow $\left.300 \mathrm{~mL} \mathrm{~min}^{-1}\right)$.

\subsection{Thermal results of the $\mathrm{Na}^{+}$salts}

The thermal events, residues, mass losses and temperature ranges observed in each step of the recorded TG/DTG and DSC curves for NaPyr, NaPip, NaMor, NaHex and NaDEDC are given in Figure 3 and Table 3.

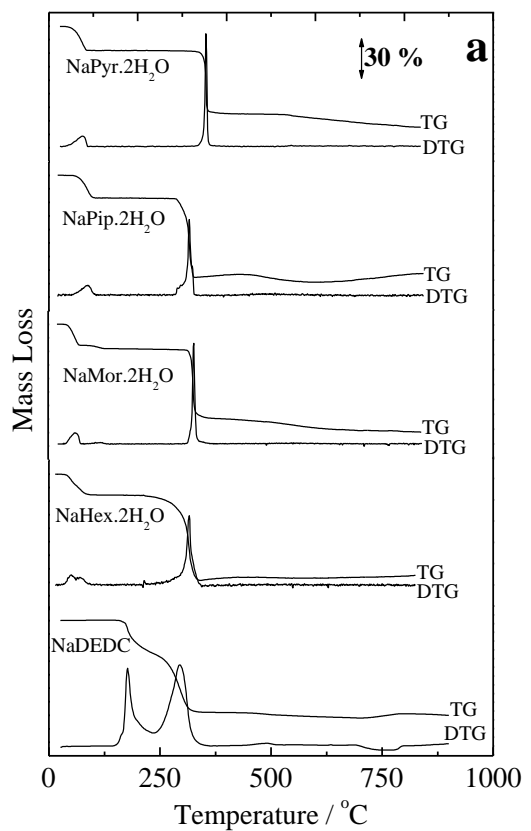

$\mathrm{NaPyr}$

The NaPyr salt showed dehydration followed by a two steps decomposition, with sodium polysulphide and a carbonaceous residue as decomposition products under nitrogen atmosphere. It was the most stable compound in the series studied the onset temperature for decomposition is $350^{\circ} \mathrm{C}$.

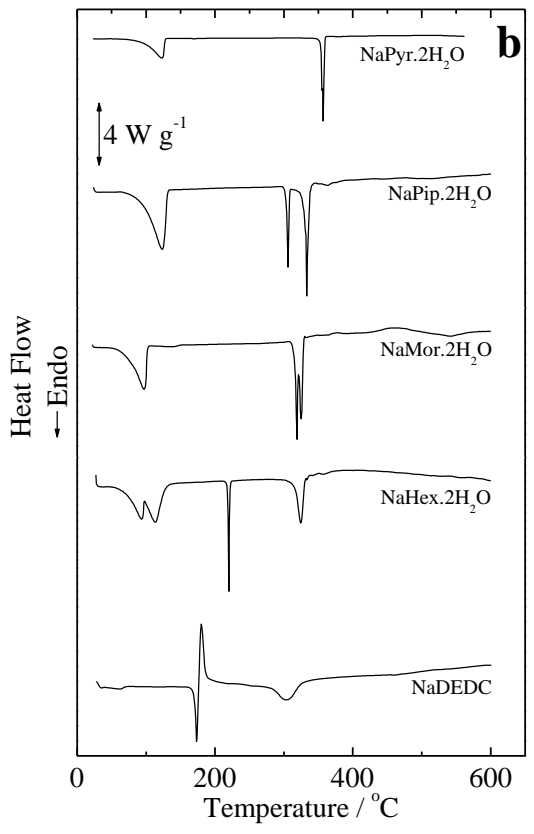

Figure 3. (a) TG/DTG curves of the salts dithiocarbamates in nitrogen atmosphere (sample mass ca. $7 \mathrm{mg}, 5^{\circ} \mathrm{C} \mathrm{min}{ }^{-1}, \mathrm{Pt}$ crucible, $\mathrm{N}_{2}$ flow $300 \mathrm{~mL} \mathrm{~min}{ }^{-1}$ ). (b) DSC curves of the salts in nitrogen atmosphere (sample mass ca. $5 \mathrm{mg}, 5^{\circ} \mathrm{C} \mathrm{m^{-1 }}$, covered Al crucible, $\mathrm{N}_{2}$ flow $300 \mathrm{~mL} \mathrm{~min}^{-1}$ ). 
Table 3. TG (mass losses, residues and temperature range) and DSC data corresponding to the decomposition of the sodium salts under nitrogen

\begin{tabular}{|c|c|c|c|c|}
\hline \multirow[t]{2}{*}{ Process } & \multirow[t]{2}{*}{$T_{\text {range }}{ }^{\circ} \mathrm{C}$} & \multicolumn{2}{|c|}{ Mass loss or residue/\% } & \multirow{2}{*}{$\begin{array}{c}\text { DSC peak } \\
\text { temperature }{ }^{\mathrm{a}} /{ }^{\circ} \mathrm{C}\end{array}$} \\
\hline & & TG & calc. & \\
\hline $\mathrm{NaPyr} .2 \mathrm{H}_{2} \mathrm{O} \rightarrow \mathrm{NaPyr}+2 \mathrm{H}_{2} \mathrm{O}$ & $39-110$ & 17,73 & 17,56 & 123 endo \\
\hline $\operatorname{NaPyr}_{(s)} \rightarrow \operatorname{NaPyr}_{(1)}$ & $340-365$ & --- & --- & 356 endo \\
\hline $\mathrm{NaPyr}_{(1)} \rightarrow$ decomposition & $300-400$ & 46,34 & --- & 359 endo \\
\hline $\mathrm{NaPip} \cdot 2 \mathrm{H}_{2} \mathrm{O} \rightarrow \mathrm{NaPip}+2 \mathrm{H}_{2} \mathrm{O}$ & $10-100$ & 16,55 & 16,43 & 123 endo \\
\hline $\operatorname{NaPip}_{(s)} \rightarrow \mathrm{NaPip}_{(1)}$ & $280-350$ & --- & --- & 306 endo \\
\hline $\operatorname{NaPip}_{(1)} \rightarrow$ decomposition & $265-340$ & 60,75 & --- & 333 endo \\
\hline NaMor.2,25 $\mathrm{H}_{2} \mathrm{O} \rightarrow$ NaMor.0, $25 \mathrm{H}_{2} \mathrm{O}+2 \mathrm{H}_{2} \mathrm{O}$ & $30-75$ & 15,44 & 15,96 & 97 endo \\
\hline NaMor. $0,25 \mathrm{H}_{2} \mathrm{O} \rightarrow$ NaMor $+0,25 \mathrm{H}_{2} \mathrm{O}$ & $80-140$ & 2,53 & 2,00 & 97 endo \\
\hline $\operatorname{NaMor}_{(\mathrm{s})} \rightarrow \operatorname{NaMor}_{(1)}$ & $300-350$ & --- & --- & 319 endo \\
\hline NaMor $_{(1)} \rightarrow$ decomposition & $290-375$ & 50,42 & --- & 325 endo \\
\hline $\mathrm{NaHex} .2 \mathrm{H}_{2} \mathrm{O} \rightarrow \mathrm{NaHex}+2 \mathrm{H}_{2} \mathrm{O}$ & $25-100$ & 15,14 & 15,44 & 96 and 119 endo \\
\hline $\mathrm{NaHex}_{(\mathrm{s})} \rightarrow \mathrm{NaHex}_{(\mathrm{s})}$ & $210-240$ & --- & --- & 220 endo \\
\hline $\mathrm{NaHex}_{(\mathrm{sl})} \rightarrow \mathrm{NaHex}_{(\mathrm{l})}+$ decomposition & $190-350$ & 62,13 & --- & 318 endo \\
\hline $\mathrm{NaDEDC} \rightarrow \mathrm{NaMor}+\mathrm{H}_{2} \mathrm{O}$ & $129-180$ & 9,00 & 8,87 & $\begin{array}{c}173 \text { endo e } \\
180 \text { exo }\end{array}$ \\
\hline NaMor $\rightarrow$ decomposition & $230-375$ & 60,47 & --- & 304 endo \\
\hline
\end{tabular}

axo - exothermic process, endo - endothermic process.

The presence of the polysulphide is in agreement with an observation in earlier works [7], and was characterized by X-ray diffraction.

The DSC curves for NaPyr salt presented two endothermic peaks attributed to a loss of water and decomposition under nitrogen atmosphere, respectively, without evidences of melting.

NaPip

This salt showed a very similar behavior to NaPyr. The decomposition occurred in two steps under nitrogen atmosphere after dehydration relative to the loss of $2 \mathrm{H}_{2} \mathrm{O}$. The two steps related to decomposition and formation of sodium polysulphide as residues were observed under nitrogen atmosphere and the residue was confirmed by $\mathrm{X}$-ray diffraction. This piperidine derivative was the second most stable compound in the series studied, with a decomposition onset temperature of $306^{\circ} \mathrm{C}$.

The DSC curve for the NaPip salt showed three endothermic peaks under nitrogen atmosphere. The first at $123{ }^{\circ} \mathrm{C}$ was related to water loss, the second a sharp peak at $306^{\circ} \mathrm{C}$, attributed to a melting process. The last one at $333^{\circ} \mathrm{C}$, attributed to the decomposition.

\section{NaMor}

The decomposition of the NaMor salt occurred in two steps under nitrogen atmosphere, after the first mass loss to the releasing $2 \mathrm{H}_{2} \mathrm{O}$. The other steps are related to decomposition and formation of sodium polysulphide as a residue under nitrogen atmosphere. This residue was confirmed by X-ray diffraction. This morpholine derivative decomposed with an onset temperature of $322{ }^{\circ} \mathrm{C}$.

The DSC curves for the NaMor salt showed three endothermic peaks under nitrogen atmosphere. The first at
$97{ }^{\circ} \mathrm{C}$ was related to water loss, the second a sharp peak at $319^{\circ} \mathrm{C}$, was attributed to a melting process. The last one at $325^{\circ} \mathrm{C}$, was attributed to the decomposition.

NaHex

The decomposition of the NaHex occurred in two steps under nitrogen atmosphere. The first step showed relative to the loss of $2 \mathrm{H}_{2} \mathrm{O}$. The second step was related to decomposition resulting in of sodium polysulphide as a residue under nitrogen atmosphere. This residue was confirmed by X-ray diffraction. This hexamethyleneimine presented an onset temperature of decomposition at $304{ }^{\circ} \mathrm{C}$.

The DSC curves for the NaHex salt showed four endothermic peaks under nitrogen atmosphere. The first showed two peaks at 96 and $119{ }^{\circ} \mathrm{C}$ was related to water loss that occurred in two steps in agreement with the DTG curve (Fig. 3.a), the second a sharp peak at $220^{\circ} \mathrm{C}$, was attributed to a melting process. The last one at $318^{\circ} \mathrm{C}$, was attributed to the decomposition.

\section{NaDEDC}

The decomposition of the anhydrous NaDEDC occurred in two steps under nitrogen atmosphere. The first related to the dehydration of the diethanolamine in order to produce morpholine [18]. The second step is related to decomposition to produce morpholine and formation of sodium polysulphide as a residue under nitrogen atmosphere. The residue was confirmed by X-ray diffraction. This diethanolamine derivative was the less stable in the series studied the onset temperature for decomposition is $170{ }^{\circ} \mathrm{C}$.

The DSC curves for the NaDEDC salt showed three peaks under nitrogen atmosphere. The onset temperature for melting is $168{ }^{\circ} \mathrm{C}$ which is followed by an exothermic event at $172{ }^{\circ} \mathrm{C}$ related to the conversion of diethanolamine to 
morpholine. The last endothermic peak at $304^{\circ} \mathrm{C}$, was attributed to the decomposition.

\subsection{Thermal results of the $K^{+}$salts}

The thermal events, residues, mass losses and temperature ranges observed in each step of the recorded TG/DTG and DSC curves for KPyr, KPip, KMor and $\mathrm{NaDEDC}$ are given in Figure 4 and Table 4.

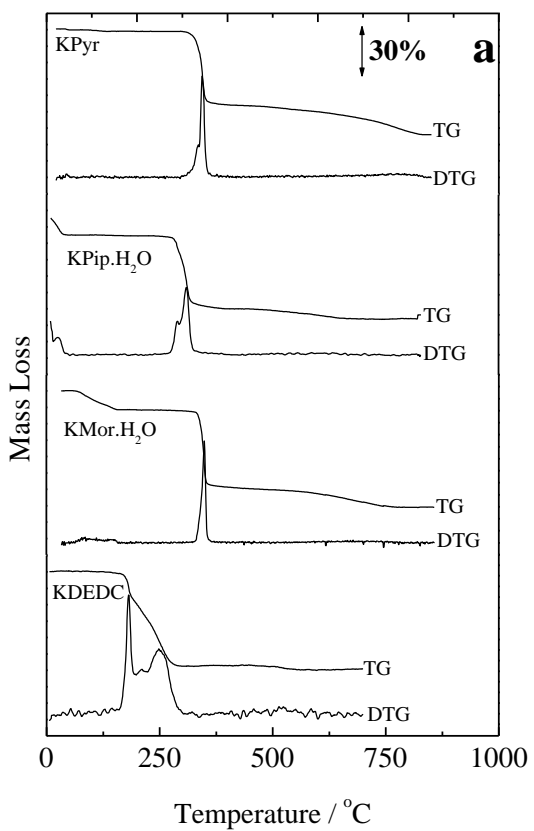

potassium thiocyanate as a residue under nitrogen atmosphere. Next KSCN decomposes to potassium polisulphide the residue was confirmed by IR. This piperidine derivative started to decompose at $292{ }^{\circ} \mathrm{C}$ onset temperature.

The DSC curves for the NaPip salt showed three endothermic peaks under nitrogen atmosphere. The first at $73{ }^{\circ} \mathrm{C}$ was related to water loss, the second a sharp peak at $305^{\circ} \mathrm{C}$, was attributed to a melting process. The last one at $331^{\circ} \mathrm{C}$, was attributed to the decomposition.

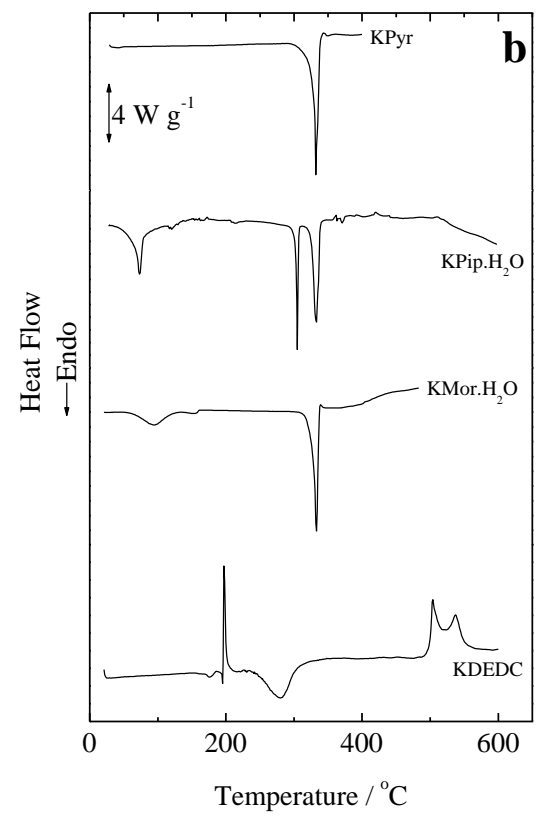

Figure 4. (a) TG/DTG curves of the salts dithiocarbamates in nitrogen atmosphere (sample mass ca. $7 \mathrm{mg}, 5^{\circ} \mathrm{C} \mathrm{min}{ }^{-1}, \mathrm{Pt}$ crucible, $\mathrm{N}_{2}$ flow $300 \mathrm{~mL} \mathrm{~min}^{-1}$ ). (b) DSC curves of the salts in nitrogen atmosphere (sample mass ca. $5 \mathrm{mg}^{\circ} 5^{\circ} \mathrm{C} \mathrm{min}{ }^{-1}$, covered $\mathrm{Al}$ crucible, $\mathrm{N}_{2}$ flow $300 \mathrm{~mL} \mathrm{~min}^{-1}$ ).

\section{KPyr}

The TG curve presented a single mass loss step between 240 and $390{ }^{\circ} \mathrm{C}$, with loss of mass of $54.25 \%$ (52.43\% calculated for $\mathrm{KSCN}$ ), the onset temperature for decomposition is $329{ }^{\circ} \mathrm{C}$. According to Sengupta and Kumar [8], the organic portion of the ligand is decomposed, resulting in the formation of the respective metal thiocyanates at the end of the first step of decomposition, as evidenced by IR analysis of the residue. The metal sulphides on heating at higher temperature lose sulphur and form nonstoichiometric metal sulphides. The KPyr salts presented decomposition in a step generating $\mathrm{KSCN}$ as residue, characterized by IR, around $400{ }^{\circ} \mathrm{C}$. The respective thiocyanates undergo decomposition at higher temperatures and the respective metal sulphides are obtained. The thiocyanate presents axial deformations of the triple bond in the area 2280 to $2000 \mathrm{~cm}^{-1}$.

The DSC curves presented an endothermic peak at $332{ }^{\circ} \mathrm{C}$ attributed to the melting of the salt.

\section{KPip}

The decomposition occurred in three steps under nitrogen atmosphere. The first relative to the loss of $2 \mathrm{H}_{2} \mathrm{O}$, the second is related to decomposition and formation of

\section{KMor}

The decomposition of the KMor salt occurred in three steps under nitrogen atmosphere. The first relative to the loss of $\mathrm{H}_{2} \mathrm{O}$. The second step is related to decomposition and formation of potassium thiocyanate as a residue under nitrogen atmosphere followed by formation of polyssulphide. All these residue were confirmed by IR. This morpholine derivative started decomposition is $340{ }^{\circ} \mathrm{C}$.

The DSC curves for the NaMor salt showed two endothermic peaks under nitrogen atmosphere. The first at $86{ }^{\circ} \mathrm{C}$ was related to water loss, the second a sharp peak at $232^{\circ} \mathrm{C}$, was attributed to a melting process. The liquid compound decomposed by endothermic processes.

\section{$K D E D C$}

This salt showed a very similar behavior to NaDEDC. The decomposition of the KDEDC occurred in two steps under nitrogen atmosphere. The first related to the dehydration of the diethanolamine in order to produce morpholine [18]. The second step is related to decomposition to produce morpholine and formation of potassium tiocyanate as a residue under nitrogen atmosphere. All these residue were confirmed by IR. 
Table 4. TG (mass losses, residues and temperature range) and DSC data corresponding to the composition of the potassium salts under nitrogen

\begin{tabular}{|c|c|c|c|c|}
\hline \multirow[t]{2}{*}{ Process } & \multirow[t]{2}{*}{$T_{\text {range }} /{ }^{\circ} \mathrm{C}$} & \multicolumn{2}{|c|}{ Mass loss or residue/\% } & \multirow{2}{*}{$\begin{array}{c}\text { DSC peak } \\
\text { temperature }{ }^{\mathrm{a}} /{ }^{\circ} \mathrm{C}\end{array}$} \\
\hline & & TG & calc. & \\
\hline $\mathrm{KPyr} \rightarrow \mathrm{KSCN}$ & $240-390$ & $54,25 *$ & $57,70 *$ & 332 \\
\hline $\mathrm{KSCN} \rightarrow$ decomposition & $390-780$ & $35,62 *$ & $30,00 *$ & --- \\
\hline KPip. $1 \mathrm{H}_{2} \mathrm{O} \rightarrow \mathrm{KPip}+1 \mathrm{H}_{2} \mathrm{O}$ & $10-70$ & 14,79 & 15,30 & 74 endo \\
\hline $\operatorname{KPip}_{(\mathrm{s})} \rightarrow \mathrm{KPip}_{(\mathrm{l})}$ & $256-293$ & 11,86 & --- & 305 endo \\
\hline $\mathrm{KPip}_{(1)} \rightarrow \mathrm{KSCN}$ & $225-409$ & $41,49 *$ & $41,28 *$ & 331 endo \\
\hline $\mathrm{KSCN} \rightarrow$ decomposition & $410-700$ & $33,78 *$ & --- & --- \\
\hline KMor. $1,4 \mathrm{H}_{2} \mathrm{O} \rightarrow \mathrm{KMor}+1,4 \mathrm{H}_{2} \mathrm{O}$ & $66-166$ & 11,30 & 11,65 & 86 endo \\
\hline $\mathrm{KMor} \rightarrow \mathrm{KSCN}$ & $323-370$ & $42,05 *$ & 42,55 & 232 \\
\hline $\mathrm{KSCN} \rightarrow$ decomposition & $400-763$ & $29,33 *$ & $24,13 *$ & --- \\
\hline $\mathrm{KDEDC} \rightarrow \mathrm{KMor}+\mathrm{H}_{2} \mathrm{O}$ & $129-180$ & 8,64 & 8,21 & $\begin{array}{l}195 \text { endo and } \\
198 \text { exo }\end{array}$ \\
\hline $\mathrm{KMor} \rightarrow \mathrm{KSCN}$ & $220-320$ & $42,60 *$ & $44,30 *$ & 280 \\
\hline $\mathrm{KSCN} \rightarrow$ decomposition & $320-700$ & 40,90 & --- & 503 and 528 endo \\
\hline
\end{tabular}

This diethanolamine derivative was the less stable in the series studied the onset temperature for decomposition is $177^{\circ} \mathrm{C}$.

The DSC curves for the KDEDC salt showed five peaks under nitrogen atmosphere. The onset temperature for melting is $194{ }^{\circ} \mathrm{C}$ followed by conversion of diethanolamine to morpholine with an exothermic peak at $195^{\circ} \mathrm{C}$. In the sequence the endothermic peaks at $208{ }^{\circ} \mathrm{C}$, and two exothermic peaks at 503 e $528{ }^{\circ} \mathrm{C}$ were attributed to the decomposition.

\section{Conclusions}

The decomposition of sodium salts occurred in different manner depending on the nature of the substituent, generating sodium polysulphites. The potassium salts decomposed via thiocyanate as predicted in the literature.

The DTC sodium salts were thermally more stable compared with the DTC potassium salts in the same DTC. The mechanism of thermal decomposition of the sodium salts do not follow the mechanism proposed by Sharma via sodium thiocyanate. What has been observed is that the decomposition mechanism leads to a residual sodium sulfide in an inert atmosphere.

Potassium salts, in turn, follows the mechanism proposed by Sharma via potassium thiocyanate intermediate, in an inert atmosphere. The order of stability for anhydrous salts was: $\mathrm{NaPyr}\left(350^{\circ} \mathrm{C}\right)<\mathrm{KMor}\left(340^{\circ} \mathrm{C}\right)<\operatorname{KPyr}\left(329^{\circ} \mathrm{C}\right)$ $<$ NaMor $\left(322^{\circ} \mathrm{C}\right)<\operatorname{NaPip}\left(306^{\circ} \mathrm{C}\right)<\mathrm{NaHex}\left(304^{\circ} \mathrm{C}\right)<$ $\operatorname{KPip}\left(292^{\circ} \mathrm{C}\right)<\operatorname{KDEDC}\left(177^{\circ} \mathrm{C}\right)<\operatorname{NaDEDC}\left(170^{\circ} \mathrm{C}\right)$.

\section{Acknowledgements}

The authors thank the FAPESP (Project 02/03448-8) for financial support of this work and PROCONTES-USP Program.

\section{Reference}

[1] Thorn GD, Ludwig RA. The dithiocarbamates and related compounds. Amsterdam: Elsevier; 1962. [Google Scholar]

[2] Nieuwenhuizen PJ, Reedijk J, Van_Duin M, McGill WJ. Thiuram and dithiocarbamate accelerated sulfur vulcanization from the chemist's perspective; methods, materials and mechanisms reviewed. Rubber Chem. Technol. 1997:70:368-429. [Google Scholar] [CrossRef]

[3] Marzano C, Trevisan A, Giovagnini L, Fregona D. Synthesis of a new platinum(II) complex: anticancer activity and nephrotoxicity in vitro. Toxicology in Vitro. 2002:16(4):413-419. [Google Scholar] [Visualizar Item] [PubMed] [CrossRef]

[4] Dithiocarbamate WHO. pesticides, ethylenethiourea and propylenethyourea: a general introduction. Environmental Health Criteria, World Health Organization. 1988:78. [Google Scholar]

[5] Hill JO. 30 Years of research in thermal-analysis and calorimetry - a personal review. J. Therm. Anal. 1994:42(2-3):607-621. [Google Scholar] [Visualizar Item] [CrossRef]

[6] Hill JO, Chirawongaram S. Thermal-analysis studies of tin dithiocarbamate complexes - a short review. J. Therm. Anal. 1994:41:511-518. [Google Scholar] [CrossRef] 
[7] Sharma AK. Thermal-behavior of metaldithiocarbamates Thermochim. Acta 1986:104:339-372. [Google Scholar] [CrossRef]

[8] Magee RJ, Jo HILL. The analytical chemistry of metal dithiocarbamate complexes. Rev. Anal. Chem. 1985:8:5-72. [Google Scholar] [CrossRef]

[9] Sengupta SK, Kumar S. Thermal studies on metal dithiocarbamato complexes - a review. Thermochim. Acta. 1984:72:349-361. [Google Scholar] [CrossRef]

[10] Hill JO, Magee RJ. The analytical chemistry of metal dithiocarbamate complexes. Rev. Inorg. Chem. 1981:3:141-197. [Google Scholar]

[11] Honjo $\mathrm{T}$, Imura $\mathrm{H}$, Shima $\mathrm{S}$, Kiba $\mathrm{T}$. Vacuum sublimation behavior of various metal-chelates of 4-anilino-3-pentene-2-one, acetylacetone, dithiocarbamates, oxine and its derivatives, dimethylglyoxime, dithizone, 1-(2-pyridylazo)-2naphthol, and tetraphenylporphyrin. Anal. Chem. 1978:50:1545-1552. [Google Scholar] [CrossRef]

[12] Fabretti AC, Forghieri F, Giusti A, Preti C, Spectroscopic TG. magnetic and thermogravimetric studies of piperazine-bis-(dithiocarbamate) complexes. Spectrochim. Acta 1984:40:343-346. [Google Scholar] [CrossRef]

[13] Cavalheiro ETG, Ionashiro M, Marino G, Breviglieri ST, Chierice GO. The effect of the aminic substituent on the thermal decomposition of cyclic dithiocarbamates. J. Braz. Chem. Soc. 1999:10(1):65-75. [Google Scholar] [Visualizar Item] [CrossRef]

[14] Polyakov AD. Vasilev AN, Optimization of the synthesis of potassium (sulfolan-3-yl) dithiocarbamate. Russ. J. Appl. Chem. 1995:68:1457-1459. [Google Scholar]

[15] Vasiliev AN. Polackov AD, Synthesis of potassium (1,1-Dioxothiolan-3-yl)-dithiocarbamate. Molecules 2000:5(8):1014-1017. [Google Scholar] [CrossRef]

[16] L A - Ramos . Estudos termoanalíticos de sais de ditiocarbamatos e aplicação eletroanalítica do piperidinoditiocarbamato de rutênio (III)". Dissertação de Mestrado, Universidade de São Paulo, Instituto de Química de São. Carlos, Brazil: 2003. [Google Scholar]

[17] Couto AB, Bernal C. Chierice GO, Cavalheiro ETG. Initial mass loss in anhydrous manganese(II) pyrrolidinedithiocarbamate. Decomposition or sublimation. J. Therm. Anal. Calorim. 2002:67:433-437. [Google Scholar] [CrossRef]
[18] Antunes PA, Breviglieri ST. Chierice GO, Cavalheiro ETG. Solution and solid state thermal stability of morpholinedithiocarbamates. J. Braz. Chem. Soc. 2001:12:473-480. [Google Scholar] [CrossRef]

[19] Bernal C, Neves EA. Cavalheiro ETG. Differences in thermal decomposition of $\mathrm{Ag}(\mathrm{I}), \mathrm{Mn}(\mathrm{II}), \mathrm{Fe}(\mathrm{II})$ and $\mathrm{Fe}$ (III) complexes of cyclic dithiocarbamates. Thermochim. Acta. 2001:370:49-55. [Google Scholar] [CrossRef

[20] Breviglieri ST, Cavalheiro ETG, Chierice GO. Correlation between ionic radius and thermal decomposition of $\mathrm{Fe}(\mathrm{II}$. $\mathrm{Co}(\mathrm{II}), \mathrm{Ni}$ (II), $\mathrm{Cu}$ (II) and $\mathrm{Zn}$ (II) diethanoldithiocarbamates. Thermochim. Acta. 2000:356:79-84. [Google Scholar] [CrossRef]

[21] Cavalheiro ETG, Ionashiro M, Marino G, Breviglieri ST, Chierice GO. Correlation between I.R. spectra and thermal decomposition of cobalt(II), nickel(II), copper(II) and mercury(II) complexes with piperidinedithiocarbamate and pyrrolidinedithiocarbamate. Transition. Met. Chem. 2000:25:69-72. [Google Scholar] [CrossRef]

[22] Breviglieri ST, Cavalheiro ETG, Chierice GO. . Studies of $\mathrm{Fe}$-III behaviour in the presence of bis(2-hydroxyethyl)dithio carbamate. Polyhedron 1996:15:839-843. [Google Scholar] [CrossRef]

[23] Nakamoto K. Infrared and Raman Spectra of Inorganic and Coordination Compounds. 3rd ed. New York: John Wiley \& Sons; 1978. [Google Scholar]

[24] Ramos LA, Cavalheiro ETG. Efeito das condições experimentais nos produtos da decomposição térmica do pirrolidinoditiocarbamato de sódio", in: III CBRATEC Congresso Brasileiro de Análise Térmica e Calorimetria, p. 49, Poços de Caldas - MG 2002. [Google Scholar] 